\title{
Structural analysis of ilmenite concentrates treated by acid-assisted high energy ball milling T.
}

\author{
García-Manzano $^{1,2}$, J. Henao-Martínez ${ }^{1}$, D. Cañas-Martínez² J. Pedraza-Avella² \\ ${ }^{1}$ Grupo de Investigación en Química Estructural- GIQUE, Universidad Industrial de Santander, Bucaramanga, Colombia \\ ${ }^{2}$ Grupo de Investigaciones en Minerales, Biohidrometalurgía y Ambiente- GIMBA, Universidad Industrial de Santander, \\ Piedecuesta, Colombia,
}

tania2188740@correo.uis.edu.co

Ilmenite is one of the most common minerals on earth crust, often found in igneous rocks and black sands of alluvial deposits and can be located in different parts around the world; it is used as natural source of $\mathrm{TiO}_{2}$ and $\mathrm{Fe}$ and as catalyst in photodegradation processes [1]. Research performed at Grupo de Investigación en Química Estructural - GIQUE and Grupo de Investigaciones en Minerales, Biohidrometalurgía y Ambiente - GIMBA using ilmenite-rich black of Barbacoas (Nariño, Colombia) for photocatalytic applications found that the specific surface area of the mineral $\left(2.4-4.2 \mathrm{~m}^{2} / \mathrm{g}\right)$ is quite low compared to that of common photocatalysts $\left(20-50 \mathrm{~m}^{2} / \mathrm{g}\right)$ [2,3]. With the aim for inducing morphological changes that lead to an increase of the surface area, that would imply more active sites available for reaction; this research proposes to submit ilmenite-rich concentrates to high energy ball milling assisted by acid solutions of acetic acid and sulfuric acid, since acids can cause changes in the distribution and oxidation state of elements on the mineral surface, thus producing pores and cracks on the surface [4,5]. However, high-energy milling in the presence of acid solutions can significantly modify the crystallography of nanostructured materials, therefore, it is important to evaluate the effect of the stress applied on particle size, surface area and composition, while tracing changes in the microstructure of ilmenite. The product of the acid treatment was obtained by evaluating the concentration of acid in the solution 1,3 and $5 \mathrm{w} / \mathrm{v} \%$, time (1-3 h), milling speed $650 \mathrm{rpm}$, ball to power weight ratio BPR (3:1, 10:1 and 20:1) and size of grinding medium (4.0 and $4.8 \mathrm{~mm})$.

Particle size distribution was measured by dynamic light scattering (DLS) and the minimum average particle size of $325 \mathrm{~nm}$ was reached by milling for $1 \mathrm{~h}$ with BPR 20:1 and size of grinding medium of $4.0 \mathrm{~mm}$. Qualitative analysis of the XRD pattern of the samples performed using the software Diffrac.EVA showed the presence of ilmenite, hematite and rutile as crystalline phases (Fig. 1) and the quantitative phase analysis in the XRD patterns reported ilmenite as the phase in greater proportion using Diffrac.TOPAS. although no changes were observed in the position of the peaks in the powder XRD patterns of the samples milled with neither the acid solutions, decreasing in the intensity and widening of the peaks were noticed (Fig. 1), which evidenced amorphization of the phases as a result of the stress applied. The morphology evaluated by scanning electron microscopy (SEM) ratify the decrease in particle size and showed different shapes of particle for both acid solutions however, it was noted that acetic acid slightly favours the decrease in particle size (Fig. 2). In order to further improve the properties of the material it was decided to increase the concentration of the acid solutions and milling time.
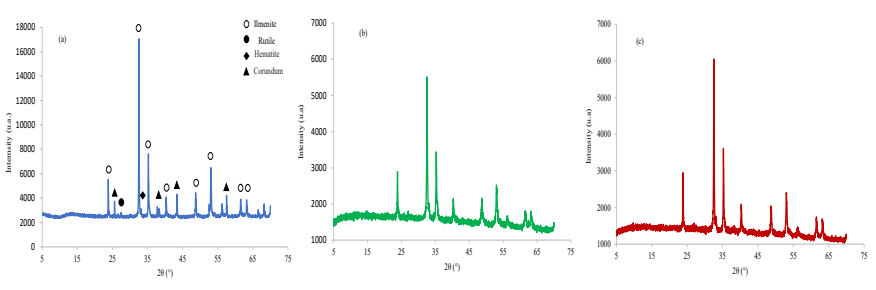

Figure 1. XRD patterns of concentrate (a) unmilled and milled in presence of (b) acetic acid and (c) sulfuric acid.

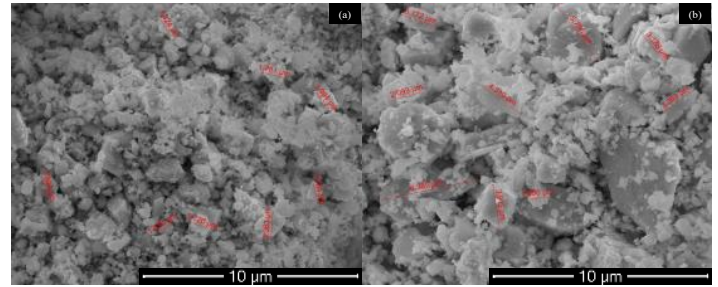

Figure 2. Micrographs comparing the particle size of milled samples with different acids: (a) acetic acid (b) sulfuric acid

[1] Y.H. Cheb, J. Non-Cryst. Solids 357 (2011) 136.

[2] D. Cañas, G. Gauthier, J. Pedraza Photochem. Photobiol. Sci 18 (2019) 912.

[3] Q. Wang, J. Lian, Y. Bai, J. Hui, J. Zhong, J. Li, N. An, J. Yu, F. Wang, Mater. Sci. Semicond. Process 40 (2015) 418.

[4] K. Hashimoto, H. Irie, A. Fujishima Jpn. J. Appl. Phys. 44 (2005) 8269.

[5] P. Parapari, M. Irannajad, A. Mehdilo, Miner. Eng 92 (2016) 160.

Keywords: Ilmenite; High energy ball milling; Acid; Microstructure; Photocatalytic

Acknowledgements to the Laboratorio de Microscopia Universidad Industrial de Santander, Colombia for the analysis of scanning electron microscopy. 